Joan Costa-Font, Daniele Fabbri and Joan Gil

Decomposing cross-country differences in levels of obesity and overweight: does the social environment matter? 


\section{Decomposing cross-country differences in levels of obesity and overweight: does the social environment matter?}

Joan Costa-Font ${ }^{\mathrm{a}}$
Daniele Fabbri $^{\text {b }}$
Joan Gil ${ }^{c}$

Working paper No. 12/2008

First Published in November 2008

LSE Health

The London School of Economics and Political Science

Houghton Street

London WC2A $2 \mathrm{AE}$

(C) Joan Costa-Font, Daniele Fabbri, Joan Gil

All rights reserved. No part of this paper may be reprinted or reproduced or utilised in any form or by any electronic, mechanical or other means, now known or hereafter invented, including photocopying and recording, or in any information storage or retrieve system, without permission in writing from the publishers.

British Library Cataloguing in Publication Data

A catalogue record for this publication is available from the British Library

ISBN [978-0-85328-005-7]

Corresponding author

Dr Joan Costa-Font

London School of Economics and Political Science

Houghton Street

London WC2A 2AE

Email: j.costa-font@1se.ac.uk

a. Department of Social Policy \& European Institute, LSE, London, UK

b. DSE, Università di Bologna, Bologna, Italy

c. Dep. of Economic Theory \& CAEPS, Universitat de Barcelona, Barcelona, Catalonia, Spain 


\section{Acknowledgements*}

We would like to thank Robert W. Fairlie for his help in interpreting his decomposition technique. We are also grateful for comments received from participants at the XXVII Jornadas de Economia de la Salud (La Coruña, June 2007) and the IHEA $6^{\text {th }}$ World Congress (Copenhagen, July 2007) and, especially, those received from John Cawley, Caroline Rudisill and Sarah Thomson on an earlier draft of this manuscript. Joan Costa-Font and Joan Gil acknowledge financial support from the Spanish Ministry of Education (Project SEJ200506270) and the Government of Catalonia (Project 2005 SGR-460 and the XREEP-Xarxa de Referència en Economia i Polítiques Públiques). 


\section{Content}

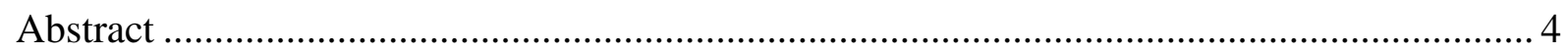

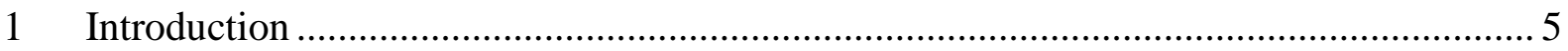

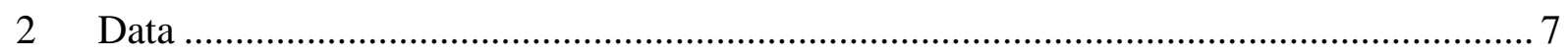

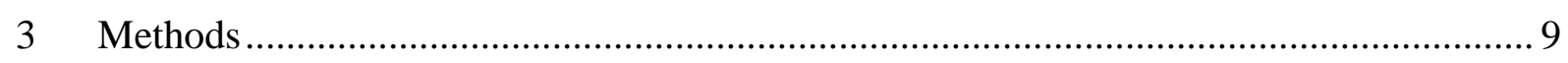

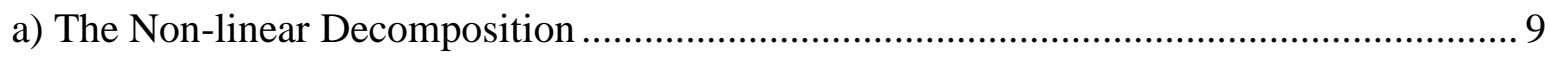

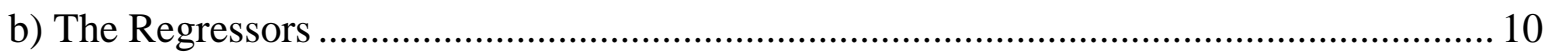

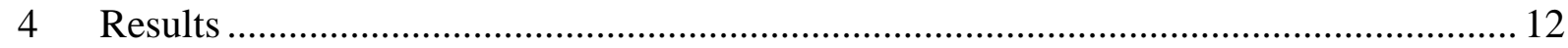

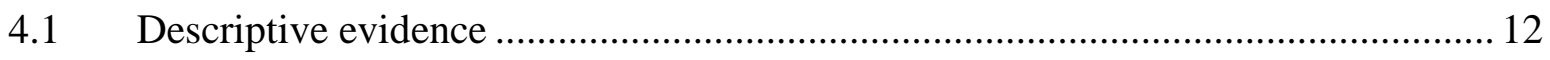

4.2 Decomposition of cross-country obesity gaps: general population ........................ 15

4.3 Decomposition of cross-country class 1 obesity gaps by age groups and gender.... 17

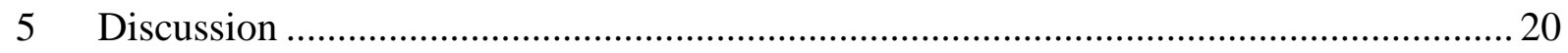

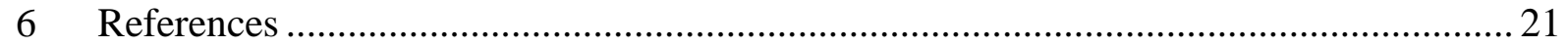

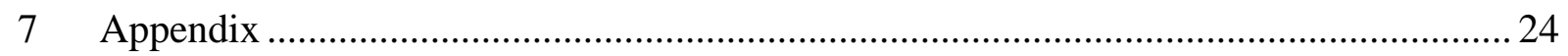




\begin{abstract}
A key question underpinning health production that remains relatively unexplored is the influence of socio-economic and environmental factors on weight gain and obesity. Such issues acquire particular relevance when data from two Mediterranean countries (Italy and Spain) are compared. Although the obesity rate was roughly the same in the two countries in 1990, by 2003 it was five percentage points higher in Spain than in Italy. This paper reports a non-linear decomposition of differences in the prevalence of overweight and obesity in Spain and Italy by gender and age. We isolate the influence of lifestyle factors and socio-economic and environmental effects in explaining cross-country differences. Our findings suggest that when the social environment (peer effects) is not controlled for, eating habits and education are the main predictors of total cross-country differences (36\% to 52\%), although these two factors have a different impact depending on gender and age. However, when we control for the social environment, these factors lose their explanatory power and peer effects are found to explain between $46 \%$ and $76 \%$ of cross-country differences and to rise with age.
\end{abstract}

Keywords: obesity, non-linear decomposition, education, Italy, Spain. 


\section{Introduction}

The recent increase in the prevalence of obesity is widely recognised as constituting a major threat to health in most western countries and is estimated to be responsible for up to $6 \%$ of total health care expenditure in Europe, as well as for generating other socio-economic costs (WHO, 2006). In the last two decades, the obesity rate has grown on average by $8 \%$ among OECD countries (Flegal et al., 2002), while its prevalence has tripled in Europe, where it now reaches epidemic proportions (Branca et al., 2007). However, on the whole, few studies have sought to explain significant cross-country differences in Europe, ${ }^{1}$ even though such research might shed valuable light on the issues underlying the problem. These major differences between countries would appear to illustrate the importance of institutional factors (e.g. education systems) and socio-environmental effects (e.g. values and lifestyles), both of which can influence the diet and physical activity (or the caloric balance) that are ultimately responsible for weight gain.

Economic theory has traditionally sought to conceptualise health production, with obesity capturing the anthropometric dimensions of health ${ }^{2}$, in terms of rational individual decisions (in the Grossman tradition) that are driven by comparisons of the costs and benefits of healthy actions. In line with this way of thinking, individuals are seen as the producers of their own health and although they receive utility from being healthy, at the same time they experience sacrifices in terms of opportunity costs from foregoing other consumption activities. In the specific case of obesity, therefore, the latter would include the pleasure gained from food intake and, in general, energy saving incentives that prevent unnecessary physical activity. However, alternative approaches call for the role of information and environmental determinants of health to be taken into consideration. Indeed, health behaviour is likely to be socially learned and, accordingly, formed in the specific community of reference, rather than to result purely from the balancing out of costs and benefits in isolation. However, whether education, in terms of the impact it might have on influencing an individual's informationprocessing capacity (Lleras-Muney, 2005 Kenkel, 1991), and social environment are behind the prevalence of obesity is an empirical question that needs to be explored further.

Current research into obesity emphasises several rational forms of behaviour. Examples of these include the impact technological changes have on the number of calories expended (Cutler et al., 2003) and the effects that more sedentary lifestyles and jobs, in combination with the effects of lower food prices resulting from agricultural innovations, are having on enhancing caloric intake (Lakdawalla and Philipson, 2002, Philipson 2001, Rashad et al., 2006, Finkelstein et al., 2005). Similarly, other incentive-driven explanations are derived from lower food prices: in particular, Chou et al. (2004) report a negative correlation between individuals' body mass index (BMI) and food prices in fast-food and full-service restaurants. Other explanations hypothesize that an increase in the rate of time preference, or the rate at which future benefits are discounted against current consumption decisions, also contribute to the obesity epidemic (Komlos, et al, 2004). Only more recently have the roles of information and, in particular, of education been recognised (Cawley et al, 2007), although the association between education and obesity appears far from clear-cut. It might be hypothesized, however,

\footnotetext{
${ }^{1}$ For instance, based on the weight and height measurements of the adult population, the prevalence of overweight individuals in Europe is estimated to range from $32 \%$ to $79 \%$ in men and from $28 \%$ to $78 \%$ in women. Obesity ranges from $5 \%$ to $23 \%$ among men and from $7 \%$ to $36 \%$ among women (Branca et al., 2007).

${ }^{2}$ Biologically speaking, weight gain is simply conceptualised as a caloric imbalance between the amount of calories ingested and those expended, in the presence of inadequate physical activity and a poor diet.
} 
that food-related health behaviours are learned from one's social environment or from one's peers, so that common patterns emerge largely from social interactions (see Lewitt, 1999, Glaeser et al., 2002). Hence, both the observed and unobserved opportunity costs of health production can be key drivers of differences obesity levels across countries.

In explaining cross-country differences in the prevalence of overweight and obesity, this paper draws on paradoxical evidence from two Mediterranean countries, Italy and Spain. Indeed, while we would not expect to find significant differences between the two countries in terms of the penetration of fast food, technology and the strenuousness of work, unusually we found large differences in the two countries' obesity rates. Thus, in 2003, self-reported obesity (as proxied by a BMI greater than 30 ) was roughly $8 \%$ in Italy and $14 \%$ in Spain, while in 1990 the rates of prevalence did not differ statistically (see Figure 1). In such a short period of time, the respective genetics of the two populations cannot provide a reasonable explanation for such differences, which can only reflect the distinct roles played by lifestyles - primarily smoking and the consumption of certain foods - and cultural patterns that affect eating behaviour, along with other effects associated with 'urban sprawl' or the propensity to take exercise (Erwing et al., 2003). All these factors arguably influence an individual's energy balance, namely the difference between energy intake and energy expenditure through physical activity. Thus, some authors report a decline in physical activity over time (in developed countries) (Bleich et al., 2007), while others describe the effects resulting from the excessive consumption of high caloric foods (Drewnoswski and Darmon, 2005). However, we need to examine the extent to which traditional lifestyles and other environmental factors explain cross-country differences in the prevalence of obesity.

Figure 1. Patterns of obesity in Italy and Spain, 1990-2003

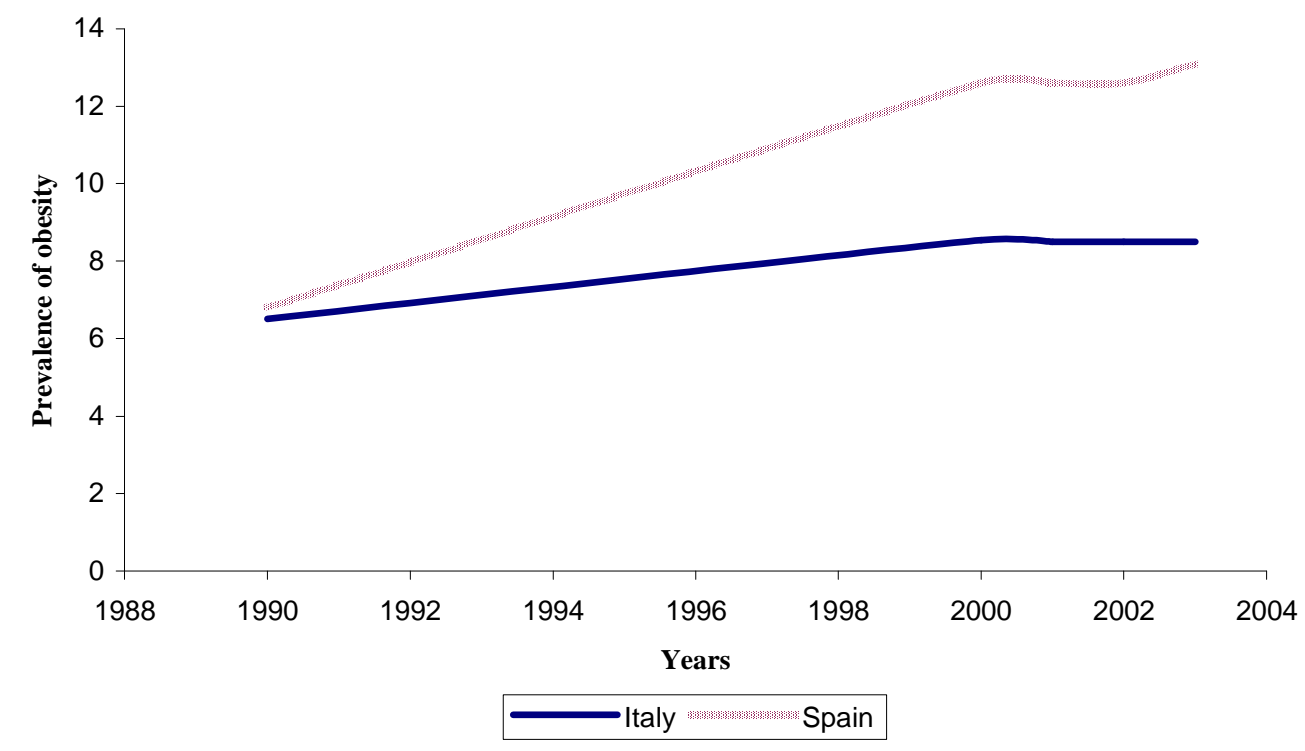

Source: OECD Health Data, 2005

This paper empirically decomposes cross-country differences in the rates of prevalence of overweight and obesity in Italy and Spain. Given that the variable of interest is binary, we draw upon methods of non-linear decomposition (Fairlie, 1999, 2005) to examine the underlying factors (including age, education and lifestyles) that might explain cross-country 
differences in overweight and obesity in two otherwise very similar Mediterranean countries. We do so by defining sub-samples according to different criteria of interest (age and gender), to identify among observable factors - aggregated into broad groups - those that account for the cross-country differences. Note that the decomposition is undertaken with and without the inclusion of peer effects - socio-environmental effects associated with area of residence - our proxy for the social environment. ${ }^{3}$ Our empirical strategy for identifying peer effects involves the selection of a regional variable, particularly relevant in Spain and Italy, which avoids individual sorting given the limited mobility in both countries.

This approach has not, to our knowledge, been previously employed for the analysis of obesity in health or nutrition, although it has been demonstrated to be specifically useful for exploring differences in binary outcomes. This paper therefore seeks to address the paucity of literature undertaking cross-country comparisons of obesity. As far as we can ascertain, the only exception here is a paper by Contoyannis and Wildman (2007) in which the authors use relative distribution analysis to examine changes in the distribution of BMI using nonparametric methods. Interestingly, in a comparison of England and Canada, their results indicate that the expansion of BMI increased at a much faster rate over time in England. However, the factors that contribute to creating this gap remain unclear. Finally, we have identified two studies that, in a similar vein to ours, examine within-country differences in obesity: between two regions in Denmark (Halkjær and Sørensen, 2004) and across Spanish regions (Gutierrez-Fisac et al., 1999). The evidence drawn from these studies suggests that differences are mainly attributable to educational level and intelligence test scores.

Our findings, on the other hand, suggest that eating habits and education are the main predictors of total cross-country differences between Italy and Spain (36-52\%). Among men, eating habits explain up to $35 \%$ of differences in levels of obesity in early adulthood, whilst education explains $43 \%$ of these differences in later adulthood. Among women, education appears to explain about $26 \%$ and $38 \%$ of the obesity difference in early and middle adulthood respectively, while eating habits only explain these differences in older adulthood (24\%). Paradoxically, when controlling for social environment in the obesity decomposition, peer effects override previous results, regardless of gender, and explain between $46-76 \%$ of total differences, a pattern that rises with age.

The rest of the paper is structured as follows. In the next section we present our data and in section three we discuss our empirical strategy. Section four reports the results and section five discusses these findings.

\section{Data}

We use cross-sectional data drawn from representative surveys for Italy and Spain. The Italian data are taken from the 2003 edition of the National Survey on Daily Life ("Indagine sugli Aspetti della Vita Quotidiana"), a survey conducted by the National Institute of Statistics (ISTAT) that collects multipurpose individual data including health conditions, health care access, dietary habits and body weight and height. The original sample contains information on 20,547 complete households comprising information from 44,384 adult individuals (aged 18 or above). The data for Spain come from the 2003 edition of the Spanish National Health Survey ("Encuesta Nacional de Salud") (SNHS), a survey conducted by the National Institute

\footnotetext{
${ }^{3}$ On determining the level of aggregation for the identification of peer effects, it is important to ensure that there is no sorting and that selection groups are narrow, because if the groups are too widely defined heterogeneity is found.
} 
of Statistics (INE) which gathers information on aspects such as self-assessed health status, primary and specialized health care utilization, consumption of medicines, lifestyles, conducts related to risk factors, anthropometrical characteristics, preventive practices and socioeconomic status. The original dataset contained 21,650 adults aged 16-99 from all Spanish regions.

Both surveys are nationally and regionally representative and use very similar sampling procedures. ${ }^{4}$ The wording of the two questionnaires is surprisingly similar, which means the information we use in the analysis is directly comparable. This means that our task of homogenizing the variables and definitions proved effective. After discarding individuals younger than 18 and older than 65 years of age and observations with missing weight and height information, we ended up with a joint dataset of 29,640 observations: 14,515 Italians and 15,125 Spaniards..$^{5}$

In line with standard practice, our dependent variable of interest is a measure of overweight and obesity based on the Quetelet index or the individual's BMI, defined as weight in kilograms divided by the square of height in meters $\left(\mathrm{kg} / \mathrm{m}^{2}\right)$. To compute this indicator, we used self-reported data on the height and weight of each respondent. Our reason for using this index lies in the fact that BMI correlates highly with body fat, while differing with age and gender. Women are more likely to have a higher percentage of body fat than men for the same BMI and, on average, older people may have more body fat than younger adults with the same BMI. ${ }^{6}$ According to the World Health Organization (2000), an individual with a BMI between 25 and $29.9 \mathrm{~kg} / \mathrm{m}^{2}$ is defined as overweight or pre-obese, while a person with a BMI of $\geq 30 \mathrm{~kg} / \mathrm{m}^{2}$ is classified as being ("class 1 ") obese. To examine cross-country differences at particular levels of obesity, adult obesity can be further sub-divided into obesity class 2 (BMI $\left.\geq 35 \mathrm{~kg} / \mathrm{m}^{2}\right)$ or severe obesity and obesity class $3\left(\mathrm{BMI} \geq 40 \mathrm{~kg} / \mathrm{m}^{2}\right)$ or morbid obesity. The importance of distinguishing between different types of obesity lies in the fact that NICE (2008) suggests that BMI might overestimate obesity below the cut-off point of 35 . In the United States, between 1986 and 2000, the prevalence of obesity class 3 quadrupled whilst class 1 doubled (Sturm, 2003; Ruhm, 2007). Furthermore, class 3 obesity seems to be the one that has experienced the largest growth levels in the United States (Freedman et al., 2002). This growth in extreme levels of obesity is of particular concern because of its consequences for mortality (Flegal et al., 2005), to the extent that it has been argued that it might reverse gains in life expectancy (Olshansky et al., 2005). ${ }^{7}$

\footnotetext{
${ }^{4}$ The SNHS-2003, for instance, follows a stratified multi-stage sampling procedure in which the primary strata are the Autonomous Communities and the sub-strata are then defined according to population size in particular areas. Within the sub-strata, municipalities and sections (primary and secondary sampling units respectively) are selected using a proportional random sampling scheme. Finally, individuals are randomly selected from the sections. The Italian National Survey on Daily Life follows a two-stage sampling procedure, with municipalities as the primary sampling units and households as the secondary sampling units. Municipalities are stratified by population size. Municipalities with populations above a certain threshold are always included, whereas the smaller ones are selected at random.

${ }^{5} \mathrm{We}$ exclude the elderly population from the sample to reduce composition bias arising from higher mortality among the more obese. Moreover this selection helps in avoiding the well-known problem of misreporting weight and height at old ages. The bias introduced in the sample when dropping missing values on weight and/or height to calculate the BMI indicator is negligible for Spain (1.8\% of total observations) and non-existent for Italy.

${ }^{6}$ Unfortunately, the BMI does not take into consideration body composition (adiposity vs. lean weight) or body fat distribution. This means it may fail to predict obesity among very muscular individuals and older people.

${ }^{7}$ However, our empirical analysis does not study obesity class 3, given its low rate of prevalence in both countries.
} 


\section{Methods}

\section{a) The Non-linear Decomposition}

Our aim here is to compute differences in the prevalence rates of overweight and obesity between the two countries by subpopulation groups and, then, to decompose these differentials into their separate underlying factors. To do this, rather than apply the traditional Blinder-Oaxaca (Blinder, 1973; Oaxaca, 1973) decomposition method to determine differences in measurable characteristics on a continuous variable, we employed Fairlie's (1999, 2005) decomposition technique, as it is particularly suited to calculating gaps for binary variables, as is the case of our prevalence rates. The procedure computes the difference in the probability of an outcome between two groups and quantifies the contribution of group differences (e.g. black/white; male/female; north/south) in the independent variables to the outcome differential.

Following Fairlie (1999), the decomposition for a non-linear equation of the type $\mathrm{P}(\mathrm{y}=1)=\mathrm{F}(\mathrm{x} \hat{\beta})$ can be expressed as,

$$
\bar{y}^{S}-\bar{y}^{I}=\left[\sum_{i=1}^{N^{S}} \frac{F\left(x_{i}^{S} \hat{\beta}^{S}\right)}{N^{S}}-\sum_{i=1}^{N^{I}} \frac{F\left(x_{i}^{I} \hat{\beta}^{S}\right)}{N^{I}}\right]+\left[\sum_{i=1}^{N^{I}} \frac{F\left(x_{i}^{I} \hat{\beta}^{S}\right)}{N^{I}}-\sum_{i=1}^{N^{I}} \frac{F\left(x_{i}^{I} \hat{\beta}^{I}\right)}{N^{I}}\right]
$$

where $\bar{y}^{j}$ is the average probability of a specific obesity class in country $j$ ( $j=S, I$ for Spain and Italy, respectively), $x^{j}$ is the set of average values of the independent variables in country $j, \hat{\beta}^{j}$ is the coefficient estimates for country $j, F$ is the cumulative distribution function from a standard normal or a logistic distribution and $N^{j}$ refers to the sample size in each country. The first term in brackets shows the part of the cross-country difference that is due to group differences in the distribution of characteristics of the independent variables, also known as 'the explained part', whereas the second term represents the portion of the cross-country difference due to differences in coefficients or 'returns' to the exogenous covariates but it also captures differences in immeasurable or unobserved endowments. Similarly, the non-linear decomposition can be written as,

$$
\bar{y}^{S}-\bar{y}^{I}=\left[\sum_{i=1}^{N^{S}} \frac{F\left(x_{i}^{S} \hat{\beta}^{I}\right)}{N^{S}}-\sum_{i=1}^{N^{I}} \frac{F\left(x_{i}^{I} \hat{\beta}^{I}\right)}{N^{I}}\right]+\left[\sum_{i=1}^{N^{S}} \frac{F\left(x_{i}^{S} \hat{\beta}^{S}\right)}{N^{S}}-\sum_{i=1}^{N^{S}} \frac{F\left(x_{i}^{S} \hat{\beta}^{I}\right)}{N^{S}}\right]
$$

where in this case the estimated coefficients for Italy, $\hat{\beta}^{I}$, are used as weights to calculate the first term of the decomposition, and the Spanish distribution of average characteristics is employed as weights for the second term. Since the decompositions of equations (3) and (4) provide different estimates, to avoid this familiar index problem in our calculations we used the coefficient estimates $\left(\hat{\beta}^{*}\right)$ from a pooled sample over all cases to weight the explained part of the decomposition (Oaxaca and Ransom, 1994).

According to Fairlie (2005), while equations (3) and (4) provide an estimate of the contribution of the explained and unexplained part to the total difference, the calculation of the separate contributions of the individual independent variables (or groups of covariates) is not direct. If one assumes that $N^{S}=N^{I}$ and $\beta^{*}$ is the probit coefficient estimates for a 
pooled sample, the individual contribution of regressor $x_{k}$ to the cross-country obesity difference can be expressed as,

$$
\frac{1}{N^{I}} \sum_{i=1}^{N^{I}} F\left(\hat{\alpha}^{*}+x_{k i}^{S} \hat{\beta}_{k}^{*}+\sum_{m \neq k} x_{m i}^{S} \hat{\beta}_{m}^{*}\right)-F\left(\hat{\alpha}^{*}+x_{k i}^{I} \hat{\beta}_{k}^{*}+\sum_{m \neq k} x_{m i}^{S} \hat{\beta}_{m}^{*}\right)
$$

which means that the contribution of a particular variable to the gap is calculated by holding constant the contribution of the other variables. ${ }^{8}$ Notice that the computation of equation (5) involves a one-to-one matching of cases between the two groups (countries) and as they typically differ in size (in our case $N^{I}<N^{S}$ ), then a large number of random sub-samples from the larger group are drawn. Each of these random sub-samples of the Spanish sample is then matched to the Italian sample and finally separate decomposition estimates are calculated. The mean value of estimates from the separate decompositions is calculated and employed to derive the results for the entire Spanish sample. ${ }^{9}$

\section{b) The Regressors}

Consistent with conventional evidence on the determinants of body weight and obesity, Table 1 presents the set of exogenous covariates employed in our econometric specifications for each country: i) the age and age square of each respondent at the date of the interview; ii) marital status by using a dummy indicating whether the individual was married or not; iii) we used three categories for educational level and one dummy variable measuring whether the individual was currently working; iv) a further dummy measured whether individuals owned private medical insurance; v) another dummy measured whether employed individuals needed to exert any physical activity in their work; vi) to capture lifestyle characteristics, we considered nine dummies for smoking habits, if respondents eat breakfast habitually and the frequency of consumption of certain foods (i.e. fish, meat and vegetables); and vii) proxying peer effects by using environmental BMI characteristics. Peer effects are measured by assuming a pure endogenous effect (Case and Katz 1991) which is not an unreasonable assumption if the research aims to examine broadly defined peer effects. We interpret peer effects widely so as to include prevailing social norms, namely people gaining utility by not deviating from the 'average' group member behaviour (Akerlof, 1997). That is, peer effects are defined as an average regional BMI level for a reference group (defined in terms of gender, age group and level of education) so that there is no bias resulting from endogenous sorting. The downside is that we cannot distinguish contextual from endogenous effects. However, this represents a persistent issue in the literature examining peer effects (Manski, 2000).

\footnotetext{
${ }^{8}$ See Fairlie (2005) for a description of how to compute the standard errors of these estimates following the delta method.

${ }^{9}$ As long as the separate contribution of an independent variable depends on the value of the other covariates, the Fairlie procedure randomizes the order of the variables to reduce the influence of the ordering on results.
} 
Table 1. Variables, definitions and means, 2003

\begin{tabular}{|c|c|c|c|c|c|}
\hline \multirow[t]{2}{*}{ Variables } & \multirow[t]{2}{*}{ Definitions } & \multicolumn{2}{|c|}{ Italy } & \multicolumn{2}{|c|}{ Spain } \\
\hline & & Female & Male & Female & Male \\
\hline & Sample size & 7,367 & 7,148 & 7,813 & 7,312 \\
\hline \multicolumn{6}{|l|}{ Dependent: } \\
\hline Overweight & $=1$ if $\mathrm{BMI}$ is between 25 and 29.9; 0 otherwise & 0.199 & 0.411 & 0.250 & 0.439 \\
\hline Obesity_1 & $=1$ if BMI is greater or equal than $30 ; 0$ otherwise & 0.068 & 0.084 & 0.115 & 0.122 \\
\hline Obesity_2 & $=1$ if BMI is greater or equal than $35 ; 0$ otherwise & 0.012 & 0.009 & 0.027 & 0.018 \\
\hline \multicolumn{6}{|l|}{ Independent: } \\
\hline \multicolumn{6}{|c|}{ Age } \\
\hline Age & Age of the interviewee individual & 41.72 & 41.61 & 39.81 & 39.48 \\
\hline Age_sq & Square of age / 100 & 19.02 & 18.83 & 17.55 & 17.26 \\
\hline \multicolumn{6}{|c|}{ Civil Status } \\
\hline Married & $=1$ if married; 0 otherwise & 0.583 & 0.554 & 0.596 & 0.574 \\
\hline \multicolumn{6}{|c|}{ Education } \\
\hline Edu_high & $=1$ if university education; 0 otherwise & 0.105 & 0.102 & 0.198 & 0.170 \\
\hline Edu_low & $=1$ if primary or lower education; 0 otherwise & 0.181 & 0.135 & 0.354 & 0.336 \\
\hline \multicolumn{6}{|c|}{ Labour Status } \\
\hline Employed & $=1$ if employed; 0 otherwise & 0.487 & 0.759 & 0.492 & 0.759 \\
\hline Work_hard & $=1$ if the employed has a "hard work" "; 0 otherwise & 0.094 & 0.224 & 0.073 & 0.254 \\
\hline \multicolumn{6}{|c|}{ Health Insurance } \\
\hline Insurance & $=1$ if owner of a private health insurance; 0 otherwise & 0.167 & 0.248 & 0.136 & 0.114 \\
\hline \multicolumn{6}{|c|}{ Life Styles } \\
\hline Curr_smoke & $=1$ if current smoker; 0 otherwise & 0.228 & 0.378 & 0.313 & 0.423 \\
\hline Past_smoke & $=1$ if quitted smoking; 0 otherwise & 0.168 & 0.250 & 0.128 & 0.201 \\
\hline Breakfast & $=1$ if regularly eats breakfast; 0 otherwise & 0.935 & 0.895 & 0.949 & 0.898 \\
\hline Nev_fish & $=1$ if eats fish less than once a week or never; 0 otherwise & 0.400 & 0.416 & 0.100 & 0.110 \\
\hline Nev_meat & $=1$ if eats meat less than once a week or never; 0 otherwise & 0.093 & 0.072 & 0.046 & 0.022 \\
\hline Nev_veget. & $=1$ if eats vegetables less than once a week or never; 0 otherwise & 0.028 & 0.055 & 0.056 & 0.097 \\
\hline Nev_fruit & $=1$ if eats fresh fruit less than once a week or never; 0 otherwise & 0.045 & 0.073 & 0.098 & 0.136 \\
\hline Nev_eggs & $=1$ if eats eggs less than once a week or never; 0 otherwise & 0.406 & 0.424 & 0.152 & 0.119 \\
\hline Nev_cereals & $=1$ if eats bread \& cereals less than once a week or never; 0 otherw. & 0.006 & 0.004 & 0.055 & 0.032 \\
\hline Nev_milk & $=1$ if eats dairy products less than once a week or never; 0 otherw. & 0.035 & 0.042 & 0.030 & 0.038 \\
\hline Nev_pasta & $=1$ if eats pasta, rice, potatoes less than once a week or never; 0 otherw. & 0.522 & 0.492 & 0.335 & 0.328 \\
\hline Nev_legu & $=1$ if eats legumes less than once a week or never; 0 otherwise & 0.536 & 0.536 & 0.164 & 0.124 \\
\hline Day_wine & $=1$ if drinks wine on a daily basis; 0 otherwise & 0.156 & 0.427 & 0.059 & 0.174 \\
\hline Day_beer & $=1$ if drinks beer on a daily basis; 0 otherwise & 0.022 & 0.115 & 0.023 & 0.118 \\
\hline Branch activ_1 & $\begin{array}{l}=1 \text { if employed in the agriculture, hunting, silviculture and fishing } \\
\text { industry; } 0 \text { otherwise }\end{array}$ & 0.029 & 0.040 & 0.020 & 0.052 \\
\hline Branch activ_2 & $=1$ if employed in the manufacture and extractive industry; 0 otherwise & 0.075 & 0.183 & 0.058 & 0.182 \\
\hline Branch activ_3 & $=1$ if employed in the construction industry; 0 otherwise & 0.006 & 0.083 & 0.008 & 0.133 \\
\hline Branch activ_4 & $\begin{array}{l}=1 \text { if employed in the whole and retail trade, motor vehicles reparation, } \\
\text { personal goods, hotels and restaurants, transport, storage and } \\
\text { communication industry; } 0 \text { otherwise }\end{array}$ & 0.116 & 0.169 & 0.138 & 0.199 \\
\hline \multicolumn{6}{|c|}{ Regional Variable } \\
\hline Peer effects & Regional average BMI level of a reference group ${ }^{* *}$ & 23.30 & 25.38 & 24.39 & 25.93 \\
\hline
\end{tabular}

Note: The reported means refer to each country's sub-sample of adults aged 18-65 (Italy N=14,515; Spain $\mathrm{N}=15,125$ ) and are computed using sampling weights.

* 'Hard work' is work that implies considerable physical exertion.

** The reference group is defined in terms of gender, age group and education level.

Source: "Encuesta Nacional de Salud 2003" (MSC) for Spain and "Indagine sugli Aspetti della Vita Quotidiana 2003” (ISTAT) for Italy. 


\section{Results}

\subsection{Descriptive evidence}

In Figure 2 we present the age distribution of the prevalence of self-reported overweight and obesity (classes 1 and 2) by gender and adults aged 18-65 in the two countries. According to this evidence, rates of overweight and obesity prevalence tend to increase as the individuals age for both genders in the two countries, although this pattern is much more pronounced in the case of Spain. Rates of prevalence in Italy always lay well below the levels reached in Spain with a cross-country gap that remained largely constant for males, but which in the case of females widened principally at older ages. Paradoxically, obesity among Spanish females seems to exhibit a rate of prevalence that is double that of Spanish males and, interestingly, both Italian males and females. Therefore, we can conclude that there are major gender/age differences that require further examination.

According to the data in Table 1, average class 1 obesity prevalence in Italy for individuals aged 18-65 years old (7.6\%) is well below that for similarly aged individuals in Spain $(11.8 \%)-4.2$ percentage points $(36 \%)$. The difference is not so great in absolute terms for class 2 obesity prevalence, but in relative terms is more than $50 \%$ lower. However, as for overweight individuals, the relative difference is much lower. Hence, Italy differs markedly from Spain, with fewer overweight and obese women throughout the entire life-cycle. Our data therefore suggest the existence of a life-cycle pattern in the generation of overweight and obesity by gender which might well be due to the interplay of a set of determinants that differs between the two populations.

Figure 2. Overweight and obesity incidence over the life cycle: Spain vs. Italy by gender, 2003

Panel A: Overweight

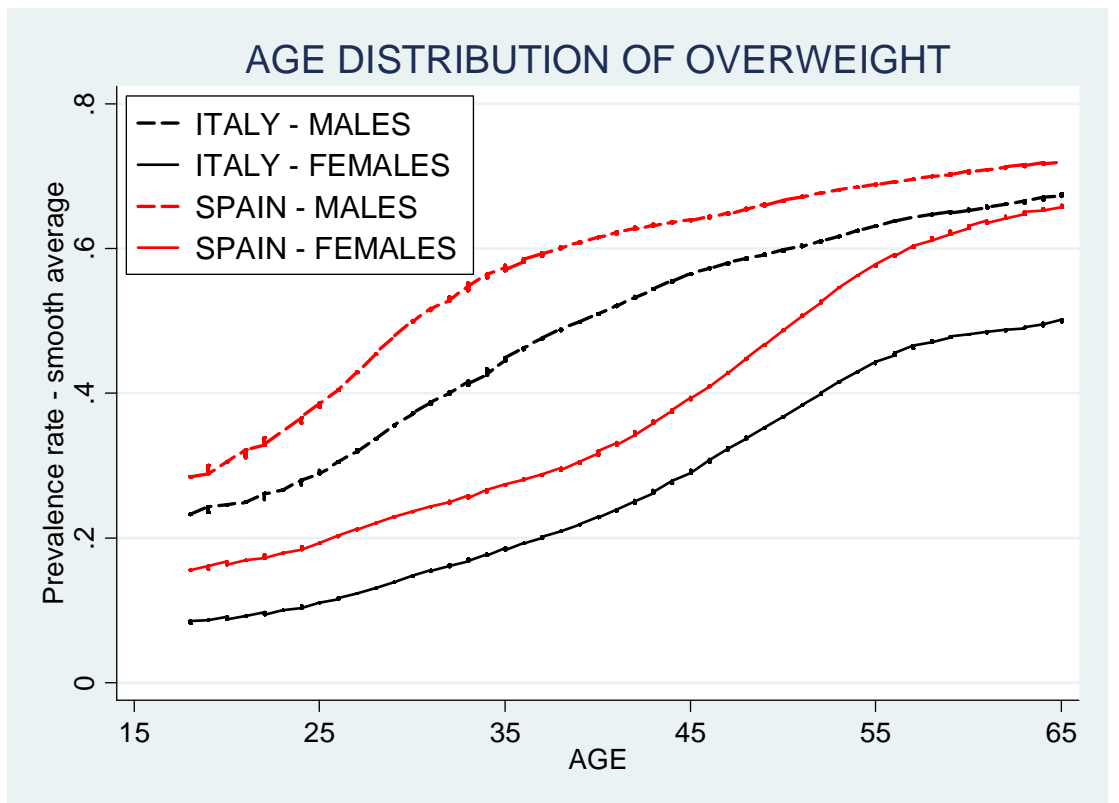

Panel B: Class 1 obesity 


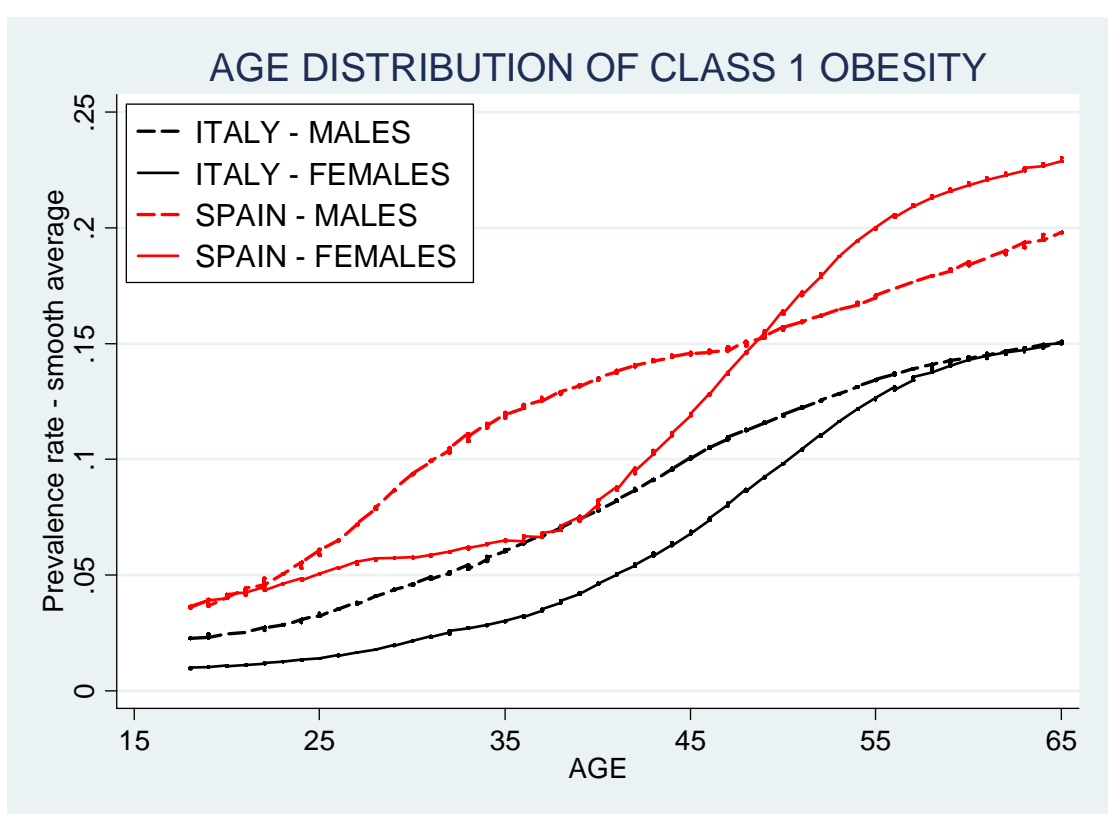

Panel C: Class 2 obesity

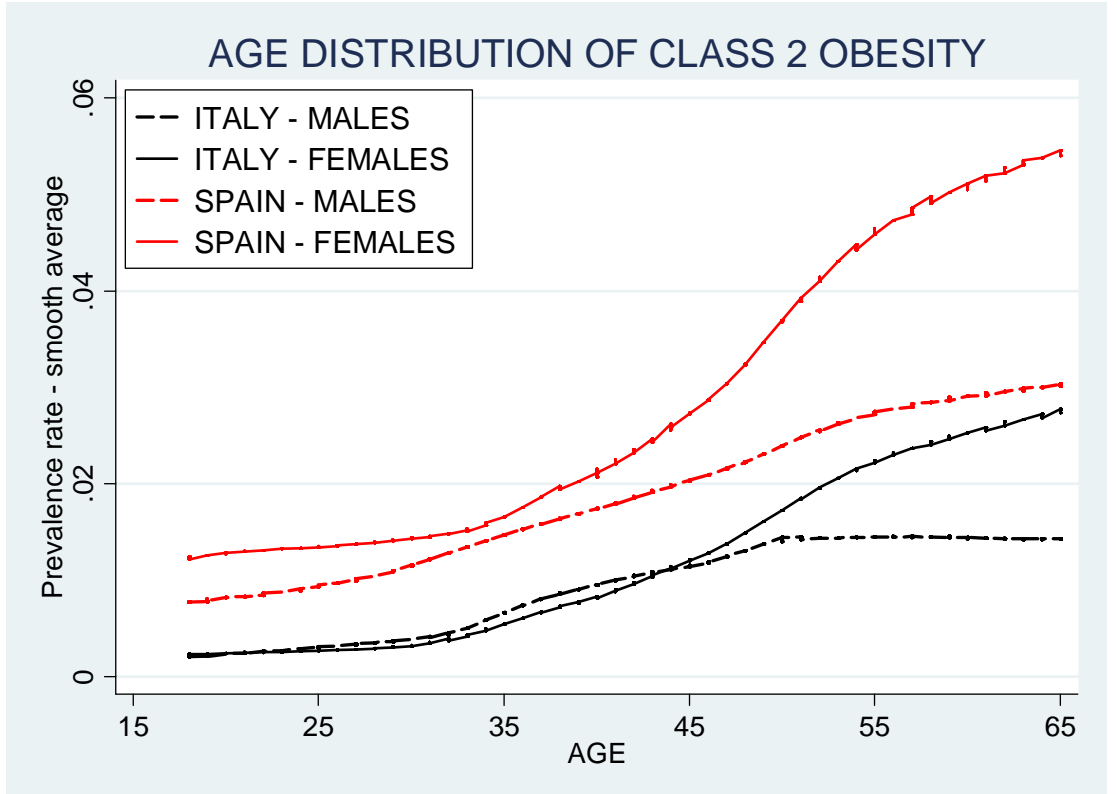

Source: "Encuesta Nacional de Salud 2003" (MSC) for Spain and "Indagine sugli Aspetti della Vita Quotidiana 2003" (ISTAT) for Italy. Note: Plots are obtained by running locally weighted regressions of the obesity indicator on age.

Table 1 also offers comparative information regarding the determinants of obesity. For instance, our sample highlights interesting differences for self-reported eating habits between two countries subject to similar general dietary patterns. While $10 \%$ of the Spanish population declares that they consume fish less than once a week or not at all, this proportion rises to more than $40 \%$ among the Italian population. In the case of meat, only about $4 \%$ of Italians eat meat on a daily or on more than a daily basis, while $19 \%$ of Spanish people declare a similar frequency of consumption. Likewise, while $41 \%$ (54\%) of Italians declare a low consumption rate of eggs (legumes) of less than once a week or never, a modest $13 \%$ (14\%) of Spanish subjects report this frequency of consumption, respectively. Interestingly, both counties show very high and moderate levels of declared daily consumption of fruits and 
vegetables, respectively. ${ }^{10}$ In terms of age, the Spanish sample is on average two years younger (39.6 vs. 41.7) owing to a larger share of individuals younger than 30 years of age. Interestingly, Spain has a more highly educated population $(18.4 \%$ vs. $10.4 \%)$, but at the same time more people with low levels of educational attainment (34.5\% vs. $15.8 \%)$. Employed status appears to be similar in both countries, as does the proportion of people with jobs that require considerable physical exertion. In the case of other lifestyle factors, Spain has a larger share of smokers (36.8\%) than Italy (30.3\%) while there is a larger number of those who have given up smoking in Italy (21\% vs. $16.4 \%)$. Strikingly, our sample also shows a remarkably higher proportion of Italians that report drinking wine on a daily basis $(29 \%$ vs. $11.6 \%$ ). Finally, as for sector specific employment, we find that percentages are quite similar. One of the advantages of using data from Italy and Spain lies in its regional heterogeneity. Given that our database is representative at the regional level, we were able to draw upon regional-specific differences to construct our peer effect variable, namely median BMI of the reference group defined by gender and age at the regional level.

To explore the determinants of obesity in each country, we ran two sets of probit regression models for the probability of being overweight (or pre-obese), obese and severely obese, comprising the full set of explanatory variables described in Table 1. Tables A1-2 in the appendix report the marginal effects of each determinant on the probability of each condition by gender in Italy and Spain, respectively. All models exhibited reasonable goodness of fit (pseudo- $\mathrm{R}^{2}$ ranging from 7 to $14 \%$ for females and from 4 to $10 \%$ for males) given the crosssectional nature of the data. The marginal effects exhibited the expected signs when estimated with acceptable precision. We found a statistically significant non-linear effect of age on the prevalence of overweight, and the same pattern was found for obesity class 1 (except for Italian men) and obesity class 2 (except for women). That is, in general overweight and obesity increase as people age until a peak is reached and then they decline. In comparative terms, it is worth noting that this age effect is stronger in the case of Spain for each obesity class and for both genders. Moreover, our results support the finding that the age impact declines in both countries as the severity of obesity increases.

Education is another important determinant of overweight and obesity. Having a university education reduces the probability of class 1 obesity in both countries and for both genders and this effect is comparatively higher in the case of Spanish women. Interestingly, education does not have a statistically significant impact on the prevalence of severe obesity in either country for men, while having a university degree reduces this condition only for Spanish women. It is also worth noting that being employed has a negative impact on the probability of class 1 and class 2 obesity among Italian women and class 2 obesity among both Italian and Spanish men. In the case of lifestyles, our findings indicate that being an active smoker reduces the probability of being overweight (with the exception of Italian men), but does not influence the chances of being obese in either Italy or in Spain. However, having smoked in the past increases the likelihood of class 1 and class 2 obesity among Italian women and class 1 obesity among Spanish men. Strikingly, dietary habits show that those that never eat fish in Spain are more likely to suffer from class 1 obesity (females) or class 2 obesity (males). Consuming no fruit is found to have a positive influence on the occurrence of class 1 and 2 obesity among the female population in Spain. ${ }^{11}$

\footnotetext{
${ }^{10}$ This evidence is compatible with the high levels of consumption of fruits and vegetables registered in both countries, well above the minimum recommended intake level of 400 grams/day (Branca et al., 2007).

${ }^{11}$ This result is compatible with the finding that higher intakes of fruits and vegetables are linked to a lower risk of becoming obese among middle-aged women, after adjusting for age and other lifestyle covariates (He et al., 2004).
} 


\subsection{Decomposition of cross-country obesity gaps: general population}

Having identified the determinants of being overweight and obesity in each country, we next examine cross-country differences in the prevalence of overweight (pre-obesity) and obesity type by gender in Table 2 . Overweight and obesity differences that are statistically significant at 5\% are larger among females than they are among males irrespective of the condition considered. This evidence suggests that differences in the characteristics of Italian women with respect to their Spanish counterparts are likely to be important in understanding this cross-country gap in overweight and obesity prevalence. 
Table 2. Probit decomposition of cross-country differences in overweight and obesity by gender

\begin{tabular}{|c|c|c|c|c|c|c|c|c|c|c|c|c|}
\hline & \multicolumn{4}{|c|}{ Overweight } & \multicolumn{4}{|c|}{ Class 1 Obesity } & \multicolumn{4}{|c|}{ Class 2 Obesity } \\
\hline & \multicolumn{2}{|c|}{ Male } & \multicolumn{2}{|c|}{ Female } & \multicolumn{2}{|c|}{ Male } & \multicolumn{2}{|c|}{ Female } & \multicolumn{2}{|c|}{ Male } & \multicolumn{2}{|c|}{ Female } \\
\hline Spanish prevalence rate $(*)$ & \multicolumn{2}{|c|}{0.448} & \multicolumn{2}{|c|}{0.265} & \multicolumn{2}{|c|}{0.128} & \multicolumn{2}{|c|}{0.117} & \multicolumn{2}{|c|}{0.018} & \multicolumn{2}{|c|}{0.028} \\
\hline Italian prevalence rate $(*)$ & \multicolumn{2}{|c|}{0.411} & \multicolumn{2}{|c|}{0.210} & \multicolumn{2}{|c|}{0.087} & \multicolumn{2}{|c|}{0.066} & \multicolumn{2}{|c|}{0.010} & \multicolumn{2}{|c|}{0.012} \\
\hline Spain/Italy gap & \multicolumn{2}{|c|}{$\mathbf{0 . 0 3 8}$} & \multicolumn{2}{|c|}{0.055} & \multicolumn{2}{|c|}{0.041} & \multicolumn{2}{|c|}{0.052} & \multicolumn{2}{|c|}{0.009} & \multicolumn{2}{|c|}{0.016} \\
\hline Contribution to difference: & Coeff. & $\%$ & Coeff. & $\%$ & Coeff. & $\%$ & Coeff. & $\%$ & Coeff. & $\%$ & Coeff. & $\%$ \\
\hline Age & -0.0053 & $-14 \%$ & -0.0008 & $-1 \%$ & -0.0028 & $-7 \%$ & -0.0015 & $-3 \%$ & -0.0006 & $-7 \%$ & -0.0004 & $-3 \%$ \\
\hline Married & 0.0032 & $8 \%$ & 0.0010 & $2 \%$ & 0.0009 & $2 \%$ & 0.0000 & $0 \%$ & -0.0001 & $-1 \%$ & -0.0002 & $-1 \%$ \\
\hline Education & -0.0008 & $-2 \%$ & 0.0108 & $20 \%$ & 0.0085 & $21 \%$ & 0.0134 & $26 \%$ & 0.0014 & $16 \%$ & 0.0045 & $28 \%$ \\
\hline Employed + physical exertion at work & 0.0007 & $2 \%$ & -0.0002 & $0 \%$ & -0.0007 & $-2 \%$ & -0.0003 & $-1 \%$ & -0.0005 & $-5 \%$ & -0.0002 & $-1 \%$ \\
\hline Branch of Activity & 0.0026 & $7 \%$ & -0.0004 & $-1 \%$ & 0.0008 & $2 \%$ & -0.0003 & $-1 \%$ & 0.0008 & $9 \%$ & -0.0001 & $-1 \%$ \\
\hline Insurance & 0.0007 & $2 \%$ & 0.0020 & $4 \%$ & 0.0015 & $4 \%$ & 0.0015 & $3 \%$ & 0.0002 & $2 \%$ & 0.0003 & $2 \%$ \\
\hline Smoking & -0.0017 & $-4 \%$ & -0.0020 & $-4 \%$ & -0.0007 & $-2 \%$ & -0.0002 & $0 \%$ & -0.0002 & $-2 \%$ & -0.0001 & $-1 \%$ \\
\hline Eating habits & 0.0143 & $38 \%$ & 0.0144 & $26 \%$ & 0.0067 & $16 \%$ & 0.0082 & $16 \%$ & 0.0035 & $39 \%$ & 0.0039 & $24 \%$ \\
\hline $\begin{array}{l}\text { All variables included } \\
\text { (total explained) }\end{array}$ & 0.014 & $36 \%$ & 0.025 & $45 \%$ & 0.014 & $34 \%$ & 0.021 & $40 \%$ & 0.005 & $51 \%$ & 0.008 & $47 \%$ \\
\hline Contribution to difference: & Coeff. & $\%$ & Coeff. & $\%$ & Coeff. & $\%$ & Coeff. & $\%$ & Coeff. & $\%$ & Coeff. & $\%$ \\
\hline Age & -0.0034 & $-9 \%$ & -0.0006 & $-1 \%$ & -0.0002 & $0 \%$ & -0.0006 & $-1 \%$ & 0.0000 & $0 \%$ & 0.0000 & $0 \%$ \\
\hline Married & 0.0031 & $8 \%$ & 0.0008 & $1 \%$ & 0.0008 & $2 \%$ & 0.0001 & $0 \%$ & -0.0001 & $-1 \%$ & -0.0003 & $-2 \%$ \\
\hline Education & -0.0039 & $-10 \%$ & -0.0006 & $-1 \%$ & 0.0027 & $6 \%$ & 0.0008 & $1 \%$ & 0.0004 & $4 \%$ & 0.0007 & $5 \%$ \\
\hline Employed + physical exertion at work & 0.0008 & $2 \%$ & -0.0002 & $0 \%$ & -0.0005 & $-1 \%$ & -0.0003 & $-1 \%$ & -0.0008 & $-9 \%$ & -0.0003 & $-2 \%$ \\
\hline Branch of Activity & 0.0025 & $6 \%$ & -0.0004 & $-1 \%$ & 0.0006 & $1 \%$ & -0.0003 & $-1 \%$ & 0.0009 & $10 \%$ & -0.0001 & $-1 \%$ \\
\hline Insurance & -0.0001 & $0 \%$ & 0.0016 & $3 \%$ & 0.0005 & $1 \%$ & 0.0011 & $2 \%$ & 0.0001 & $1 \%$ & 0.0002 & $1 \%$ \\
\hline Smoking & -0.0016 & $-4 \%$ & -0.0021 & $-4 \%$ & -0.0006 & $-1 \%$ & -0.0005 & $-1 \%$ & -0.0002 & $-2 \%$ & -0.0002 & $-1 \%$ \\
\hline Eating habits & 0.0069 & $18 \%$ & 0.0050 & $9 \%$ & -0.0022 & $-5 \%$ & -0.0008 & $-2 \%$ & 0.0021 & $24 \%$ & 0.0011 & $7 \%$ \\
\hline Peer effects & 0.0206 & $54 \%$ & 0.0408 & $74 \%$ & 0.0264 & $64 \%$ & 0.0396 & $76 \%$ & 0.0041 & $46 \%$ & 0.0121 & $76 \%$ \\
\hline $\begin{array}{l}\text { All variables included } \\
\text { (total explained) }\end{array}$ & 0.025 & $65 \%$ & 0.044 & $81 \%$ & 0.027 & $67 \%$ & 0.039 & $75 \%$ & 0.007 & $74 \%$ & 0.013 & $83 \%$ \\
\hline
\end{tabular}

Note: $(*)$ Unweighted overweight and obesity prevalence rates. To perform the decomposition an (unweighted) probit regression model on a pooled sample was run to derive the $\beta$ coefficients (not shown). Contribution estimates are the mean values of the decomposition using 100 sub-samples of Spanish. The order of the variables in each replication has been randomised. Coefficients statistically significant at 5\% (10\%) are in bold (italic) typeface. 
Table 2 shows Fairlie's decomposition of the cross-country gaps in overweight and the two obesity classes. We conducted the decomposition by gender, alternatively excluding and including the control for peer effects. The set of determinants we inserted in the model are able to explain, depending on the obesity type considered, between 34 and $51 \%$ of the overall cross-country gaps (i.e. the 'explained part' or due to differences in the distribution of characteristics) when no peer effect was included. However, these determinants explain between 65 and $83 \%$ of gaps when the peer effect is controlled for. When no peer effect is included, country differences in eating behaviour explain 38 and $26 \%$ of the cross-country gaps in overweight among men and women respectively, while education explains $20 \%$ of the cross-country overweight gaps among women but not among men. Interestingly, whilst the contribution of education increases to $21-26 \%$ for the obesity class 1 gap and the effect of eating habits stays at $16 \%$, about $40 \%$ of cross-country gaps in obesity class 2 among men are explained by eating habits and $24 \%$ among women, although in the case of the latter group education explains as much as $28 \%$ of the class 2 obesity gaps. Overall, our results indicate that there are significant lifestyle factors contributing to make Spanish people more obese than their Italian counterparts. This result is consistent with, for instance, Cutler et al. (2003) and Bleich et al. (2007) suggesting that an excess of caloric intake might be the factor responsible for the rise of obesity. However, when peer effects were included in the model, we found that they alone explain between 46 and $76 \%$ of total cross-country variability and that they override the effect of other covariates.

\subsection{Decomposition of cross-country class 1 obesity gaps by age groups and gender}

Figure 2 not only shows markedly different patterns between men and women, but also quite distinct age-specific effects in the case of obesity. Therefore, in this section we concentrate our analysis on the decomposition of cross-country differences in class 1 obesity by age groups and gender. Results indicate that cross-country class 1 obesity gaps between Spanish and Italian men lie in the range of 3-4\% for the youngest and oldest age groups and rise to $5.4 \%$ for those in the middle cohort (36-50 year olds) (Table 3). However, among women these differences are much greater and increase progressively with age, reaching 8 percentage points in the 51-65 age group.

On examining the contributing factors, we found that the explained part of the cross-country gap for men varies significantly from one age group to another: from as much as $51 \%$ for younger adults to just $15 \%$ for the older adults. However, when peer effects were introduced we found that the differences in the distribution of characteristics (independent variables) explain between $70-84 \%$ of the cross-country gap in class 1 obesity (Table 3 ). A similar pattern was found for women: the explained part of the total gap ranges from 35-49\% without peer effects and from 70-100\% when these effects are included (Table 4).

Moreover, Table 3 reveals that for men, at early ages, cross-country differences in class 1 obesity are mainly explained by eating behaviour; in middle adulthood both eating behaviour and education play a role, while in later adulthood gaps are explained by education alone. A different pattern was found for women: in early adulthood $26 \%$ of the class 1 obesity gap can be explained by education while eating habits explain just $16 \%$, education alone explains $38 \%$ in middle adulthood, and both education and eating habits explain 22-24\% of the gap in latter adulthood. Here again, the introduction of peer effects overrides education and eating habits in explaining gaps in obesity rates. 
Table 3. Probit decomposition of cross-country differences in obesity by age cohorts (males only)

\begin{tabular}{|c|c|c|c|c|c|c|}
\hline & \multicolumn{6}{|c|}{ Class 1 Obesity. Male } \\
\hline & \multicolumn{2}{|c|}{ Age cohort 18-35 } & \multicolumn{2}{|c|}{ Age cohort 36-50 } & \multicolumn{2}{|c|}{ Age cohort 51-65 } \\
\hline Spanish prevalence rate $(*)$ & \multicolumn{2}{|c|}{0.072} & \multicolumn{2}{|c|}{0.143} & \multicolumn{2}{|c|}{0.181} \\
\hline Italian prevalence rate $(*)$ & \multicolumn{2}{|c|}{0.037} & \multicolumn{2}{|c|}{0.088} & \multicolumn{2}{|c|}{0.143} \\
\hline Spain/Italy obesity gap & \multicolumn{2}{|c|}{$\mathbf{0 . 0 3 5}$} & \multicolumn{2}{|c|}{0.054} & \multicolumn{2}{|c|}{0.038} \\
\hline Contribution to difference: & Coeff. & $\%$ & Coeff. & $\%$ & Coeff. & $\%$ \\
\hline Married & -0.0004 & $-1 \%$ & 0.0027 & $5 \%$ & -0.0002 & $0 \%$ \\
\hline Education & 0.0040 & $11 \%$ & 0.0104 & $19 \%$ & 0.0163 & $43 \%$ \\
\hline Employed + physical exertion at work & 0.0001 & $0 \%$ & 0.0004 & $1 \%$ & -0.0015 & $-4 \%$ \\
\hline Branch of Activity & -0.0004 & $-1 \%$ & 0.0022 & $4 \%$ & 0.0005 & $1 \%$ \\
\hline Insurance & 0.0020 & $6 \%$ & 0.0006 & $1 \%$ & -0.0009 & $-2 \%$ \\
\hline Smoking & 0.0003 & $1 \%$ & 0.0004 & $1 \%$ & -0.0011 & $-3 \%$ \\
\hline Eating habits & 0.0122 & $35 \%$ & 0.0083 & $15 \%$ & -0.0072 & $-19 \%$ \\
\hline All variables included (total explained) & 0.018 & $51 \%$ & 0.025 & $46 \%$ & 0.006 & $15 \%$ \\
\hline Contribution to difference: & Coeff. & $\%$ & Coeff. & $\%$ & Coeff. & $\%$ \\
\hline Married & -0.0002 & $0 \%$ & 0.0021 & $4 \%$ & -0.0002 & $-1 \%$ \\
\hline Education & -0.0014 & $-4 \%$ & 0.0038 & $7 \%$ & 0.0012 & $3 \%$ \\
\hline Employed + physical exertion at work & 0.0003 & $1 \%$ & 0.0002 & $0 \%$ & -0.0010 & $-3 \%$ \\
\hline Branch of Activity & -0.0008 & $-2 \%$ & 0.0018 & $3 \%$ & 0.0001 & $0 \%$ \\
\hline Insurance & 0.0013 & $4 \%$ & -0.0011 & $-2 \%$ & -0.0026 & $-7 \%$ \\
\hline Smoking & 0.0003 & $1 \%$ & -0.0002 & $0 \%$ & -0.0008 & $-2 \%$ \\
\hline Eating habits & 0.0037 & $11 \%$ & -0.0073 & $-13 \%$ & -0.0196 & $-51 \%$ \\
\hline Peer Effects & 0.0260 & $74 \%$ & 0.0459 & $85 \%$ & 0.0498 & $130 \%$ \\
\hline All variables included (total explained) & 0.029 & $83 \%$ & 0.045 & $84 \%$ & 0.027 & $70 \%$ \\
\hline
\end{tabular}

Note: $(*)$ Unweighted obesity prevalence rates. To perform the decomposition an (unweighted) probit regression model on a pooled sample was run to derive the $\beta$ coefficients (not shown). Contribution estimates are the mean values of the decomposition using 100 sub-samples of Spanish. The order of the variables in each replication has been randomised. Coefficients statistically significant at 5\% (10\%) are in bold (italic) typeface. 
Table 4. Probit decomposition of cross-country differences in obesity by age cohorts (females only)

\begin{tabular}{|c|c|c|c|c|c|c|}
\hline & \multicolumn{6}{|c|}{ Class 1 Obesity. Female } \\
\hline & \multicolumn{2}{|c|}{ Age cohort 18-35 } & \multicolumn{2}{|c|}{ Age cohort 36-50 } & \multicolumn{2}{|c|}{ Age cohort 51-65 } \\
\hline Spanish prevalence rate $(*)$ & \multicolumn{2}{|c|}{0.051} & \multicolumn{2}{|c|}{0.102} & \multicolumn{2}{|c|}{0.215} \\
\hline Italian prevalence rate $(*)$ & \multicolumn{2}{|c|}{0.016} & \multicolumn{2}{|c|}{0.053} & \multicolumn{2}{|c|}{0.139} \\
\hline Spain/Italy obesity gap & \multicolumn{2}{|c|}{$\mathbf{0 . 0 3 5}$} & \multicolumn{2}{|c|}{$\mathbf{0 . 0 4 9}$} & \multicolumn{2}{|c|}{0.076} \\
\hline Contribution to difference: & Coeff. & $\%$ & Coeff. & $\%$ & Coeff. & $\%$ \\
\hline Married & -0.0020 & $-6 \%$ & -0.0004 & $-1 \%$ & -0.0003 & $0 \%$ \\
\hline Education & 0.0091 & $26 \%$ & 0.0185 & $38 \%$ & 0.0165 & $22 \%$ \\
\hline Employed + physical exertion at work & 0.0004 & $1 \%$ & 0.0005 & $1 \%$ & -0.0012 & $-2 \%$ \\
\hline Branch of Activity & -0.0004 & $-1 \%$ & -0.0012 & $-2 \%$ & 0.0000 & $0 \%$ \\
\hline Insurance & 0.0001 & $0 \%$ & 0.0016 & $3 \%$ & 0.0027 & $4 \%$ \\
\hline Smoking & 0.0010 & $3 \%$ & -0.0015 & $-3 \%$ & 0.0015 & $2 \%$ \\
\hline Eating habits & 0.0055 & $16 \%$ & -0.0004 & $-1 \%$ & 0.0185 & $24 \%$ \\
\hline All variables included (total explained) & 0.014 & $40 \%$ & 0.017 & $35 \%$ & 0.038 & $49 \%$ \\
\hline Contribution to difference: & Coeff. & $\%$ & Coeff. & $\%$ & Coeff. & $\%$ \\
\hline Married & -0.0021 & $-6 \%$ & -0.0005 & $-1 \%$ & -0.0002 & $0 \%$ \\
\hline Education & 0.0001 & $0 \%$ & -0.0031 & $-6 \%$ & -0.0016 & $-2 \%$ \\
\hline Employed + physical exertion at work & 0.0006 & $2 \%$ & 0.0005 & $1 \%$ & -0.0015 & $-2 \%$ \\
\hline Branch of Activity & -0.0003 & $-1 \%$ & -0.0013 & $-3 \%$ & 0.0002 & $0 \%$ \\
\hline Insurance & 0.0000 & $0 \%$ & 0.0013 & $3 \%$ & 0.0019 & $3 \%$ \\
\hline Smoking & 0.0006 & $2 \%$ & -0.0016 & $-3 \%$ & -0.0009 & $-1 \%$ \\
\hline Eating habits & 0.0010 & $3 \%$ & -0.0096 & $-20 \%$ & -0.0033 & $-4 \%$ \\
\hline Peer Effects & 0.0240 & $70 \%$ & 0.0473 & $96 \%$ & $\mathbf{0 . 0 8 2 7}$ & $109 \%$ \\
\hline All varsiables included (total explained) & 0.024 & $70 \%$ & 0.033 & $67 \%$ & 0.077 & $100 \%$ \\
\hline
\end{tabular}

Note: (*) Unweighted obesity prevalence rates. To perform the decomposition an (unweighted) probit regression model on a pooled sample was run to derive the $\beta$ coefficients (not shown). Contribution estimates are the mean values of the decomposition using 100 sub-samples of Spanish. The order of the variables in each replication has been randomised. Coefficients statistically significant at 5\% (10\%) are in bold (italic) typeface. 


\section{Discussion}

This paper has attempted to address a puzzling and empirically innovative question as to what lies behind cross-country differences in overweight and obesity prevalence rates. It has also attempted to clarify the role played by education, lifestyles and environmental factors, namely peer effects. In seeking to answer this question we have undertaken an empirical study of two countries, Italy and Spain. Both countries reported similar rates of obesity in 1990, but by 2003 there was a difference of five percentage points in their respective prevalence rates. After identifying the key theoretical determinants of the health production function observable in our data, we performed a non-linear decomposition of the cross-country overweight and obesity (class 1 and class 2) differences, with and without accounting for peer effects. Accounting for peer effects is justified on the understanding that cross-country differences should shed some light on the factors underpinning the obesity epidemic insofar as they are not driven by random processes. Comparing Italy and Spain is a particularly useful exercise as both countries share similar characteristics (i.e. the Mediterranean diet) and enjoy similar levels of technology and socio-economic development. However, these countries are subject to significantly different social norms and values regarding body shape and, accordingly, their behaviour towards food differs (Eurobarometer, 2005).

Both descriptive analyses and statistical inferences based on multivariate methods suggest that certain health production factors, including lifestyles, employment and education, are likely to influence overweight and obesity in each country. Our key findings suggest that cross-country differences in overweight and obesity can be largely explained by differences in eating habits and education, although we identified different behavioural patterns between men and women. However, when controlling for socio-environmental factors, peer effects override such covariate effects, regardless of gender, and explain between $46 \%$ and $76 \%$ of total differences, a pattern that increases with age.

While this study supports previous research highlighting the importance of socioenvironmental effects on obesity rates, we find that the impact of societal norms (in the form of average BMI within the population in which an individual lives) is a key determinant of obesity levels. This finding does not suggest that socio-environmental effects no longer play a role, but that their influence may be captured through the variable used to proxy peer effects.

Age-specific effects are interesting and indicate that obesity rates reach their height at age 5565 , irrespective of the country and gender under review. But the effect of age on prevalence among Spanish females is twice that of Spanish males and Italians of both genders. The main driver of this difference appears to be related to lifestyle and education, especially at older ages. One explanation of these effects might lie in the different impact of the social values attached to keeping in good shape and being fit in the two countries, and the consequent effect this has on lifestyles. Other explanations might include the growing consumption of processed foods as people struggle to find time to prepare their own meals, as well as a rising dependence on comfort foods. All in all, these results imply that preventive policies have a key role to play in improving lifestyles in those countries that exhibit marked increases in obesity rates. And yet obesity prevention also needs to influence environmental sources of social health learning and more, specifically, the role of social norms, which we have shown as being country specific. 
Finally, a certain degree of caution must be adopted in interpreting our results given that this is the first attempt to decompose cross-country differences in obesity rates. In this sense, the use of self-reported information on weight and height (instead of measured anthropometric data) might impact the definition of overweight and obesity and hence affect the robustness of our results. However, this problem is to some extent addressed by excluding individuals older than 65 years old from the sample, as this group is typically the main source of misreporting.

\section{References}

Akerlof, G. (1997). Social Distance and Social Decisions. Econometrica 65(5): 1005-1027.

Bleich, S., Cutler, D., Murray, C. and Adams, A. (2007). Why Is the Developed World Obese? NBER Working Paper No. 12954.

Blinder, A.S. (1973). Wage Discrimination: Reduced Form and Structural Variables. Journal of Human Resources, 8, 436-455.

Branca, F., Nikogosian, H. and Lobstein, T. (2007). The Challenge of Obesity in the WHO European Region and the Strategies for Response. World Health Organization 2007.

Case, A.C. and Katz, L.F. (1991). The Company You Keep: The Effects of Family and Neighborhood on Disadvantaged Youths, NBER Working Paper No. 3705.

Cawley, J., Meyerhoefer, C. and Newhouse, D. (2007). The Impact of State Physical Education Requirements on Youth Physical Activity and Overweight. Health Economics, 16(12): 1287-1301.

Chou, S.Y., Grossman, M. and Saffer, H. (2004). An Economic Analysis of Adult Obesity: Results from the Behavioural Risk Factor Surveillance System, Journal of Health Economics 23: $565-587$.

Contoyannis, P. and Wildman, J. (2007). Using Relative Distributions to Investigate the Body Mass Index in England and Canada, Health Economics 16: 929-944.

Cutler, D.M., Glaeser, E.L. and Shapiro, J.M. (2003). Why Have Americans Become More Obese? Journal of Economic Perspectives, 17(3): 93-118.

Drewnowski, A. and Darmon, N. (2005). The Economics of Obesity: Dietary Energy Density and Energy Cost, American Journal of Clinical Nutrition, 82 (suppl.): 265S-73S.

Erwing, R., Schmid, T. and Killigsworth, R., Zlot, A. and Radenbush, S. (2003). Relationship between Urban Sprawl and Physical Activity, Obesity and Morbidity. American Journal of Health Promotion, 18(1): 47-57.

Encuesta Nacional de Salud (2003). Minsitry of Heaslth and Consumprion, Madrid.

Eurobarometer \# 64.3: Foreign Languages, Biotechnology, Organized Crime and Health Items, November-December 2005, ICPSR- 4590. 
Fairlie, R.W. (1999). The Absence of the African-American Owned Business: An Analysis of the Dynamics of Self-Employment, Journal of Labour Economics, 17(1): 80-108.

Fairlie, R.W (2005). An extension of the Blinder-Oaxaca Decomposition Technique to Logit and Probit models, Journal of Economic and Social Measurement, 30(4): 305 - 316.

Finkelstein, E.A., Ruhm, C.J. and Kosa, K.M. (2005). Economic Causes and Consequences of Obesity, Annual Review of Public Health, 26: 239-257.

Flegal, H.M., Caroll, M.D., Ogden, C.L. and Johnson, C.L. (2002). Prevalence and Trends in Obesity Among US Adults, 1999-2000, International Journal of Obesity, 22: 39-47.

Flegal, K.M., Graubard, M.D., Williamson, D.F. and Gail, M.H. (2005). Excess Death Associated with Underweight, Overweight and Obesity, JAMA, 293: 1861-67.

Freedman, D.S., Kahn, L.K., Serdula, M.K., Galuska, D.A. and Dietz, W.H. (2002). Trends and Correlates of Class 3 Obesity in the United States from 1900 through 2000, JAMA, 288: 1758-1762.

Glaeser, E.L., Sacerdote, B. and Scheinkman, J. (2002). The Social Multiplier, NBER Working Paper No. 9153.

Gutierrez-Fisac, J.L., Artalejo, F., Guallar-Castillon, P., Banegas, J. and Calero, J. (1999) Determinants of Geographical Variations in Body Mass Index and Obesity in Spain, International Journal of Obesity and Related Metabolic Disorders 23: 342-347.

Halkjær, J. and Sørensen, T.I.A. (2004). Psychosocial and Demographic. Determinants of Regional Differences in the Prevalence of Obesity, Journal of Biosocial Science 36: 141-152.

He, K., Hu, F.B., Colditz, G.A., Manson, J.E., Willett, W.C. and Liu, S. (2004). Changes in Intake of Fruits and Vegetables in Relation to Risk of Obesity and Weight Gain Among Middle-Aged Women, International Journal of Obesity, 28(12): 1569-1574.

Indagine sugli Aspetti della Vita Quotidiana (2003). ISTAT, Rome.

Kenkel, D.S. (1991). Health Behaviour, Health Knowledge and Schooling, Journal of Political Economy, 92(2): 287-305.

Komlos, J., Smith, P.K. and Bogin, B. (2004). Obesity and the Rate of Time Preference: Is there a connection?, Journal of Biosocial Science 36: 209-219.

Lakdawalla, D. and Philipson, T. (2002). The Growth of Obesity and Technological Change: A Theoretical and Empirical Examination, NBER Working Paper No 8946.

Lewitt, S.D. (1999). The Limited Role of Changing Age Structure in Explaining Aggregate Crime Rates, Criminology 37(3): 581-597. 
Lleras-Muney, A. (2005). The Relationship between Education and Adult Mortality in the United States, The Review of Economic Studies, 72(1): 189-221.

NICE (2008). Obesity: the Prevention, Identification, Assessment and Management of Overweight and Obesity in Adults and Children. National Institute for Health and Clinical Excellence (NICE), 2006. Available at: http://www.nice.org.uk/guidance/CG43

Manski, C. (2000). Economic Analysis of Social Interactions, Journal of Economic Perspectives 68(3):115-36

Oaxaca, R. (1973). Male-Female Wage Differentials in Urban Labor Markets, International Economic Review 14, 693-709.

Oaxaca, R. and Ransom, M. (1994). On Discrimination and the Decomposition of Wage Differentials, Journal of Econometrics 61: 5-21.

OECD (2005). Health Data, Paris.

Olshansky, S.J., Passaro, D.J., Hershow, R.C., Layden, J. Carnes, B.A., Brody, J. et al. (2005). A Potential Decline in Life Expectancy in the United States in the $21^{\text {st }}$ Century, New England Journal of Medicine 352: 1138-1145.

Philipson, T. (2001). The World-Wide Growth in Obesity: An Economic Research Agenda, Health Economics 10(1): 1-7.

Rashad, I. Grossman, M. and Chou, S. (2006). The Super Size of America: An Estimation of Body Mass Index and Obesity in Adults, Eastern Economic Journal 32(1): 133-148.

Ruhm, C. J. (2007). Current and Future Prevalence of Obesity and Severe Obesity in the United States. NBER, Working Paper No. 13181.

Sturm, R. (2003). Increases in Clinically Severe Obesity in the United States, 1986-2000, Annals of Internal Medicine, 163: 2146-2148.

WHO (2000). Obesity: Preventing and Managing the Global Epidemic. Report of a WHO Consultation. WHO Technical Report Series 894. Geneva, Switzerland, World Health Organisation.

WHO (2006) European Charter on Counteracting Obesity, World Health Organisation, Europe, Copenhagen. 


\section{Appendix}

Table A1. Marginal Effects for Overweight \& Obesity Covariates (Females only)

\begin{tabular}{|c|c|c|c|c|c|c|}
\hline & \multicolumn{2}{|c|}{ Overweight } & \multicolumn{2}{|c|}{ Class 1 Obesity } & \multicolumn{2}{|c|}{ Class 2 Obesity } \\
\hline & ITALY & SPAIN & ITALY & SPAIN & ITALY & SPAIN \\
\hline Age & 0.0103 & 0.0100 & 0.0057 & 0.0065 & 0.0008 & 0.0010 \\
\hline Age_sq & -0.0092 & -0.0073 & -0.0051 & -0.0064 & -0.0008 & -0.0012 \\
\hline Married & 0.0467 & 0.0309 & -0.0049 & 0.0103 & -0.0047 & -0.0023 \\
\hline Edu_high & -0.0208 & -0.0422 & -0.0198 & -0.0364 & -0.0026 & -0.0139 \\
\hline Edu_low & 0.0263 & -0.0081 & -0.0030 & 0.0153 & -0.0002 & 0.0057 \\
\hline Employed & -0.0063 & -0.0047 & -0.0160 & -0.0101 & -0.0049 & -0.0020 \\
\hline Work_hard & 0.0232 & 0.0328 & 0.0042 & -0.0124 & -0.0052 & -0.0060 \\
\hline Curr_smoke & -0.0296 & -0.0555 & 0.0042 & -0.0267 & 0.0013 & -0.0047 \\
\hline Past_smoke & -0.0060 & -0.0238 & 0.0205 & -0.0269 & 0.0059 & -0.0051 \\
\hline Breakfast & -0.0213 & -0.0412 & -0.0096 & -0.0355 & -0.0017 & -0.0109 \\
\hline Nev_meat & -0.0079 & -0.0225 & -0.0129 & -0.0065 & -0.0027 & 0.0003 \\
\hline Nev_fish & -0.0034 & -0.0110 & 0.0016 & 0.0268 & -0.0008 & 0.0023 \\
\hline Nev_vege & -0.0061 & 0.0312 & 0.0005 & 0.0023 & -0.0017 & 0.0016 \\
\hline Nev_fruit & -0.0153 & -0.0218 & -0.0117 & 0.0336 & -0.0011 & 0.0069 \\
\hline Nev_eggs & -0.0008 & 0.0156 & 0.0041 & -0.0021 & 0.0006 & -0.0017 \\
\hline Nev_cereals & -0.0386 & 0.0193 & -0.0298 & 0.0301 & --- & 0.0082 \\
\hline Nev_milk & 0.0357 & 0.0308 & 0.0211 & -0.0156 & 0.0026 & 0.0056 \\
\hline Nev_pasta & 0.0171 & 0.0265 & 0.0066 & 0.0160 & 0.0018 & 0.0027 \\
\hline Nev_legu & -0.0156 & -0.0002 & 0.0041 & $\mathbf{0 . 0 2 2 7}$ & -0.0009 & 0.0057 \\
\hline Day_wine & 0.0064 & 0.0061 & -0.0154 & -0.0233 & -0.0034 & -0.0034 \\
\hline Day_beer & -0.0261 & -0.0493 & -0.0258 & -0.0268 & -0.0028 & -0.0150 \\
\hline Insurance & -0.0184 & $-\mathbf{0 . 0 3 3 7}$ & -0.0068 & -0.0283 & -0.0006 & -0.0038 \\
\hline Branch activ_1 & -0.0048 & 0.0468 & 0.0103 & 0.0211 & --- & 0.0094 \\
\hline Branch activ_2 & -0.0217 & -0.0206 & 0.0211 & -0.0084 & 0.0161 & -0.0019 \\
\hline Branch activ_3 & -0.0991 & -0.1030 & --- & -0.0077 & --- & 0.0356 \\
\hline Branch activ_4 & -0.0256 & -0.0082 & 0.0045 & -0.0126 & 0.0016 & -0.0039 \\
\hline Peers Effect & 0.0352 & 0.0268 & 0.0169 & 0.0247 & $\mathbf{0 . 0 0 3 3}$ & 0.0059 \\
\hline No. Of Obs. & 6,944 & 7,813 & 6,909 & 7,813 & 6,673 & 7,813 \\
\hline Pseudo $\mathrm{R}^{2}$ & 0.080 & 0.067 & 0.125 & 0.129 & 0.140 & 0.106 \\
\hline Obs. P & 0.210 & 0.265 & 0.066 & 0.117 & 0.013 & 0.028 \\
\hline (Pred. P) & 0.190 & 0.249 & 0.043 & 0.087 & 0.006 & 0.017 \\
\hline
\end{tabular}

Note: Standard errors adjusted for clustering on region nominal variable. Statistical significance at 5\% (10\%) in bold (italic) typeset. 
Table A2. Marginal Effects for Overweight \& Obesity Covariates (Males only)

\begin{tabular}{|c|c|c|c|c|c|c|}
\hline & \multicolumn{2}{|c|}{ Overweight } & \multicolumn{2}{|c|}{ Class 1 Obesity } & \multicolumn{2}{|c|}{ Class 2 Obesity } \\
\hline & ITALY & SPAIN & ITALY & SPAIN & ITALY & SPAIN \\
\hline Age & 0.0146 & 0.0215 & 0.0018 & 0.0083 & 0.0012 & 0.0017 \\
\hline Age_sq & -0.0119 & -0.0210 & -0.0012 & -0.0088 & -0.0013 & -0.0017 \\
\hline Married & 0.0687 & 0.0922 & 0.0184 & 0.0117 & -0.0009 & -0.0023 \\
\hline Edu_high & 0.0023 & -0.0309 & -0.0230 & -0.0214 & -0.0050 & -0.0044 \\
\hline Edu_low & -0.0047 & -0.0231 & -0.0102 & 0.0222 & 0.0017 & 0.0006 \\
\hline Employed & 0.0310 & 0.0101 & 0.0005 & -0.0134 & -0.0059 & -0.0131 \\
\hline Work_hard & 0.0123 & -0.0045 & 0.0006 & -0.0124 & -0.0020 & 0.0027 \\
\hline Curr_smoke & 0.0171 & -0.0321 & 0.0000 & -0.0043 & -0.0007 & -0.0015 \\
\hline Past_smoke & 0.0373 & 0.0200 & -0.0008 & 0.0225 & 0.0021 & 0.0002 \\
\hline Breakfast & -0.0178 & -0.0021 & -0.0440 & -0.0559 & -0.0037 & -0.0094 \\
\hline Nev_meat & 0.0036 & -0.0857 & -0.0237 & -0.0108 & 0.0001 & -0.0061 \\
\hline Nev_fish & 0.0166 & -0.0047 & -0.0017 & 0.0185 & 0.0002 & 0.0117 \\
\hline Nev_vege & -0.0089 & -0.0241 & -0.0177 & -0.0013 & 0.0003 & -0.0002 \\
\hline Nev_fruit & 0.0312 & -0.0032 & 0.0078 & -0.0150 & 0.0059 & -0.0022 \\
\hline Nev_eggs & -0.0024 & 0.0125 & 0.0153 & 0.0165 & 0.0001 & -0.0004 \\
\hline Nev_cereals & 0.0175 & 0.0904 & --- & 0.0220 & --- & 0.0137 \\
\hline Nev_milk & -0.0104 & -0.0495 & -0.0125 & -0.0122 & --- & 0.0024 \\
\hline Nev_pasta & 0.0068 & -0.0229 & 0.0075 & 0.0273 & 0.0014 & 0.0047 \\
\hline Nev_legu & -0.0097 & 0.0108 & 0.0024 & 0.0185 & -0.0038 & 0.0032 \\
\hline Day_wine & 0.0026 & 0.0188 & -0.0052 & -0.0070 & -0.0044 & -0.0016 \\
\hline Day_beer & 0.0404 & -0.0229 & 0.0056 & 0.0026 & 0.0005 & -0.0023 \\
\hline Insurance & -0.0093 & 0.0287 & -0.0030 & 0.0086 & 0.0000 & -0.0002 \\
\hline Branch activ_1 & 0.0427 & 0.0590 & 0.0071 & 0.0370 & 0.0097 & 0.0117 \\
\hline Branch activ_2 & -0.0319 & 0.0275 & -0.0135 & -0.0095 & 0.0050 & -0.0042 \\
\hline Branch activ_3 & 0.0324 & 0.0213 & -0.0113 & -0.0081 & 0.0030 & 0.0027 \\
\hline Branch activ_4 & 0.0195 & 0.0044 & -0.0110 & 0.0329 & 0.0030 & 0.0104 \\
\hline Peers Effect & 0.0386 & 0.0173 & 0.0361 & 0.0340 & 0.0032 & 0.0050 \\
\hline No. Of Obs. & 6,702 & 7,312 & 6,803 & 7,312 & 6,415 & 7,312 \\
\hline Pseudo $\mathrm{R}^{2}$ & 0.044 & 0.038 & 0.081 & 0.063 & 0.102 & 0.063 \\
\hline Obs. P & 0.411 & 0.448 & 0.087 & 0.128 & 0.010 & 0.018 \\
\hline (Pred. P) & 0.405 & 0.445 & 0.070 & 0.112 & 0.005 & 0.014 \\
\hline
\end{tabular}

Note: Standard errors adjusted for clustering on region nominal variable. Statistical significance at $5 \%(10 \%)$ in bold (italic) typeset. 


\section{For further information on this or any of the}

Health publications contact:

Champa Heidbrink

Managing Editor

LSE Health

The London School of Economics and Political Science

Houghton Street

London WC2A 2AE

Tel: + 44 (0)20 79556840

Fax: + $44(0) 2079556090$

Email: c.heidbrink@|se.ac.uk

Website: www.Ise.ac.uk/collections/LSEHealth/ 